\title{
Los comienzos de la investigación en la Facultad de Humanidades y Ciencias, UNL
}

Solidario Romero ${ }^{(1)}$

(1) Ex Director de Investigación de la FHUC.
Las actividades institucionalizadas de investigación en la Escuela Universitaria del Profesorado empezaron formalmente en 1987.

Este enunciado no significa desconocer que antes de ese momento, y desde la existencia del Instituto del Profesorado Básico, no haya habido investigaciones. Pero eran producidas por el esfuerzo voluntario y espontáneo de Profesores de la Casa -mencionemos a Delia Travadello, Juan Manuel Jozami, Mabel G. Gallardo, Rubén Manzi, a modo de ejemplo-que trabajaban en sus respectivos campos disciplinares (Letras, Ciencias Naturales, Geografía, etc.) acompañados por algunos docentes de su Equipo de Cátedra, casi siempre sin presupuesto y sin haber recibido formación epistemológica y metodológica curricular formal.

Durante el Decanato Normalizador del Prof. Mauricio G. Epelbaum, que creó un Área de Investigación -semilla de la futura Secretaría de Investigación- se instituyó e impulsó la realización de proyectos de investigación formalizados, concursados y calificados por evaluadores externos, dentro de un marco institucional normalizado. 
Esta decisión, tendiente a la construcción institucional de una Facultad, con los atributos académicos que la constituyen como tal, logró promover una serie de Equipos de Investigación entrenados y capacitados para la práctica formal institucionalizada de la investigación (Proyectos concursados, con evaluación externa, con roles de investigación asignados, con evaluación externa del Informe Final de Investigación, etcétera).

Este período de capacitación creó la base real para hacer posible la participación de los investigadores de la facultad en el llamado a concurso de Proyectos de Investigación en el sistema creado por la UNL (Curso de Acción para la Investigación y el Desarrollo: C.A.I+D) y ante otros entes como el CONICET, que normalmente imponen condiciones más rigurosas a los proyectos de investigación.

El notable crecimiento cualitativo y cuantitativo de proyectos gestados por los docentes investigadores de la Facultad, y la alta proporción de proyectos aprobados por los Evaluadores Externos demostraron el acierto que significó la institución de la etapa preparatoria.

Así, se arribó a un tercer momento evolutivo, donde los Docentes Investigadores de la Facultad produjeron Programas de Investigación, constituidos por numerosos Proyectos que logran aprobación en el Consejo Superior de la Universidad los primeros, y por parte de la Secretaría de Ciencia y Técnica, UNL, los segundos.

Así se alcanzaron dos importantes finalidades institucionales: (1) la realización de investigaciones, como atributo necesario de la vida académica de la Facultad; y (2) la existencia de Investigadores y de Equipos de Investigación con vigencia real y actividad permanente en la producción de nuevos conocimientos. Es muy importante valorar el esfuerzo de los profesores que hicieron investigación -1984 a 1990-, en un momento en que aún no existía el Programa de Incentivos a los Docentes Investigadores, porque el insumo básico eran los tiempos y las energías obtenidos sobreponiéndose a las fatigas de la tarea docente, con base en el espíritu académico para construir una auténtica Facultad Universitaria, y en muchos casos con aporte económico personal. Y 
en la mayoría de los casos, haciendo un esfuerzo autodidáctico serio, individual o grupal, para formarse como investigadores.

\section{Logros de la institucionalización de las actividades de investigación.}

Las consecuencias del proceso descrito consistieron en la creación de un clima o atmósfera académica donde comenzó a "naturalizarse" la fusión de la docencia con la investigación, donde la figura del profesor universitario empezó a verse con naturalidad como integrada por las funciones de enseñar e investigar, cuestión que antes existió sólo parcialmente en el ámbito de la Escuela de Profesorado.

Otra consecuencia positiva consistió en que se aprendió a concursar, a someter proyectos a evaluadores externos, a producir informes de avances, a exponer los resultados parciales de cada etapa en congresos y cursos, todo lo cual confluyó en el desarrollo de una cultura del investigar institucionalmente formalizado. Otro saldo positivo fue, primero, la creación y luego la existencia permanente de equipos de investigación multigeneracionales, con al menos tres niveles de experiencia y formación: el investigador formado, los investigadores en proceso de formación, y los ingresantes al campo de la investigación que comienzan sus aprendizajes. En el interior del equipo los directores desarrollaron sus habilidades para formar investigadores; otros consolidaron su vocación y capacidades investigativas; y los más jóvenes pasaron de ser estudiantes/aprendices a capacitarse para ser productores de conocimiento.

\section{Vinculaciones fecundas con los posgrados y tesistas.}

El impulso y desarrollo de las actividades de investigación ocurrió paralelamente con la creación de los Estudios de Posgrado (la Maestría en Ecología Acuática Continental fue el primero de ellos). Se produjo así una relación complementaria entre los Seminarios componentes de cada Maestría, los Docentes Inves- 
tigadores a cargo de ellos, los Proyectos de Investigación y la producción de Tesis por parte de los maestrandos. Este proceso central en una vida académica organizada continúa hasta el presente con una integración progresiva entre los tres campos.

\section{La integración de los investigadores mediante los programas de investigación.}

En los inicios de la actividad institucionalizada y formalizada de la FHUC (en aquella época Facultad de Formación Docente en Ciencias), enmarcados en el C.A.I+D de la UNL se integran Proyectos de Investigación formalmente institucionalizados a cargo de equipos donde realizan su formación graduados y alumnos. No se puede dejar de destacar la claridad y decisión del Decano Normalizador, Prof. Mauricio G. Epelbaum, para crear un Área de Investigación dependiente del Decanato, que a través de sucesivas etapas (Cursos de formación para la investigación, Concursos Internos de Proyectos, redacción de Programas, presentación y evaluación de Proyectos al C.A.I+D, impulso a la presentación de Proyectos al Programa de Cientibecas, etc.) convirtió una idea de política universitaria en una realidad académica real y concreta.

Precisamente, el autor de esta nota fue el responsable del Área de Investigación desde su creación y por espacio de dos períodos de gestión.

Recordemos cuáles fueron los Programas y Proyectos con los que la Facultad de Formación Docente en Ciencias -era su nombre en aquella época- ingresa al Curso de Acción para la Investigación y Desarrollo de la UNL:

\section{- Convocatoria 89-90:}

(1) "Desarrollo progresivo y experimental de las didácticas especiales, para el Nivel Universitario, en el área de Santa Fe", integrado por cuatro Proyectos de tres Facultades (FHUC, FIQ, FBCB).

(2) "Experiencia interdisciplinarias de los lenguajes en la interacción dinámica Texto/Contexto", integrado por dos Proyectos de la FHUC. 
- Convocatoria 93-94

(1) "Desarrollo de condiciones para la investigación e investigaciones propiamente dichas en el campo de la enseñanza y aprendizaje de las ciencias en el Nivel Universitario", integrado por once Proyectos pertenecientes a cuatro Facultades (FHUC, FAVE, FBCB, FIQ).

(2) "Pensamiento, lenguaje y semiósis en las prácticas educativas," integrado por cuatro Proyectos pertenecientes a la FHUC.

(3) "Programa de estudios interdisciplinarios de Historia Social" integrado por dos Proyectos pertenecientes a la FHUC.

- Convocatoria 94-95

(1) "Calidad de la Educación y Formación universitaria: su investigación y evaluación", integrado por dos Proyectos pertenecientes a la FIQ y a la FHUC.

(2) "Estructura y funciones de los discursos", integrado por seis Proyectos pertenecientes a la FHUC.

\section{- Convocatoria 1996}

(1) "Las mujeres como actores sociales" integrado por cuatro Proyectos pertenecientes a la FHUC y la FAVE.

(2) "Programa de estudios interdisciplinarios de Historia Social" integrado por siete Proyectos de la FHUC.

(3) "Ecosistemas regionales perturbados por acción antropogénica. Su incidencia sobre la Biodiversidad" integrado por cinco Proyectos pertenecientes a la FHUC y FAVE).

(4) "Concentración coordinada de investigaciones sobre la Enseñanza y el Aprendizaje universitarios" integrados por veintiséis Proyectos pertenecientes a la FHUC, la FAVE, FBCB, FIQ, FCE, y el ISM).

Con posterioridad a la convocatoria C.A.I+D 1996 la FHUC (en aquel entonces Facultad de Formación Docente en Ciencias) contiene en su seno, de manera 
permanente e integrada, Equipos de Investigación, que presentan sus Programas de I+D a todas las convocatorias posteriores.

Los Profesores de la Casa que redactaron y firmaron los primeros Programas arriba enumerados, fueron, por orden alfabético: Carlos Caudana, Elsa Ghío, Darío Macor, Jorge Malachevsky, Mercedes Marchese, Solidario Romero y Teresa Suárez.

\section{A modo de balance.}

La perspectiva que otorga el tiempo permite decir que dos cualidades caracterizaron el comienzo de la investigación institucionalizada: la gradualidad y la responsabilidad.

Gradualidad, porque se dieron los pasos necesarios para capacitar a los directores y a los noveles investigadores integrantes de los equipos -incluida la constitución de éstos- en la preparación de proyectos capaces de sostener la evaluación ante jueces externos calificados.

Responsabilidad, porque el proceso de formación de los equipos de investigación por afinidad de propósitos, sin imperativos de la autoridad, y su capacitación mediante la "puesta a prueba" frente a evaluadores externos protegió al personal académico de la Casa de la exposición a posibles fracasos cuando se formalizó la investigación frente al C.A.I+D de la Universidad.

Debe valorarse otra situación: la capacitación interna en la Facultad y el Curso de Acción para la Investigación y el Desarrollo de la Universidad crearon una atmósfera de impulso y motivación hacia la investigación formalizada. Por influencia recíproca, por afán imitativo, por competencia intelectual, por auténtico descubrimiento de la satisfacción que conlleva la producción de conocimientos, inclinaron a la mayoría de los profesores de una Escuela predominantemente docente, hacia otra mayoría, de docentes-investigadores de una Facultad. 
Así como existía una Escuela centrada en la enseñanza, con algunas investigaciones más personales que institucionalizadas, de actividad fundamentalmente docente, veinte años después nos encontramos con una Facultad donde la mayoría de sus docentes dirigen o integran proyectos de investigación formalmente institucionalizados a cargo de equipos donde realizan su formación graduados y alumnos.

No se puede dejar de mencionar la claridad y decisión del Decano normalizador Prof. Mauricio G. Epelbaum para crear un Área de Investigación dependiente del Decanato que en sucesivas etapas -Concursos Internos, presentación de Programas, presentación de Proyectos C.A.I+D, impulso a la presentación de Proyectos al Programa de Cientibecas-, etc. convirtió una idea de política universitaria en una realidad académica concreta. 